\title{
Aeration Strategy at Birth Does Not Impact Carotid Blood Flow and Oxygen Delivery in Preterm Lambs
}

Dahm $\mathrm{S}^{1}$, Kenna $\mathrm{KR}^{1}$, Stewart $\mathrm{D}^{1,2}$, Pereira-Fantini $\mathrm{PM}^{1,3}$, McCall KE ${ }^{1,2}$, Perkins $\mathrm{EJ}^{1,2}$,

Sourial $\mathrm{M}^{1}$, Tingay $\mathrm{DG}^{1,2,3}$

${ }^{1}$ Neonatal Research, Murdoch Children's Research Institute, Parkville, Australia

${ }^{2}$ Department of Neonatology, The Royal Children's Hospital, Parkville, Australia

${ }^{3}$ Department of Paediatrics, The University of Melbourne, Parkville, Australia

\section{Corresponding Author:}

Dr Sophia Dahm MD

Neonatal Research

Murdoch Children's Research Institute

50 Flemington Rd

Parkville Victoria 3052

Australia

$+61393454023$

Sophia.dahm@mcri.edu.au

Running Title: Carotid blood flow at birth

Keywords: Preterm, infant; electrical impedance tomography, extubation, continuous positive applied pressure

Word Count: 2534 words

Preprint: A preprint version is available at biorxiv.org 


\section{Ethics Approval and Reporting}

The study were approved by the Animal Ethics Committee of the Murdoch Children's Research Institute, Melbourne, Australia (A780, A790, A822) in accordance with National Health and Medical Research Council guidelines and is reported as per the ARRIVE guidelines.

Author contributions: DGT and PP-F developed the concept and designed the experiment. DGT, PP-F, EJP, KEMcC, MS were involved in lamb experimental work. SD, KRK, DS performed the carotid and cerebral data analysis. All authors participated in data interpretation. DGT supervised all aspects of the study and subsequent data analysis. SD wrote the first draft and all authors contributed to redrafting the manuscript.

Financial Support: This study is supported by a National Health and Medical Research Council Project Grant (Grant ID 1009287) and the Victorian Government Operational Infrastructure Support Program (Melbourne, Australia). DGT was supported by a National Health and Medical Research Council Clinical Career Development Fellowship and Investigator Grant (Grant ID 1053889 and 2008212). Chiesi Farmaceutici S.p.A. (Parma, Italy) provided the Curosurf used in this study as part of an unrestricted grant to DGT at the Murdoch Children's Research Institute. Chiesi Farmaceutici had no involvement in study design, implementation, analysis, interpretation or reporting.

Competing interests: The other authors have no competing interests to declare.

Data Sharing: All data, including raw data used for all figures and analysis, is available upon request to the corresponding author from three months following article publication to researchers who provide a methodologically sound proposal, with approval by an independent review committee ("learned intermediary"). Proposals should be directed to 
bioRxiv preprint doi: https://doi.org/10.1101/2022.03.03.482754; this version posted March 4, 2022. The copyright holder for this preprint (which was not certified by peer review) is the author/funder, who has granted bioRxiv a license to display the preprint in perpetuity. It is made available under aCC-BY-NC-ND 4.0 International license.

david.tingay@mcri.edu.au to gain access. Data requestors will need to sign a data access or material transfer agreement approved by MCRI. 


\section{What is already known on this topic}

Facilitating the respiratory transition at birth for preterm infants is essential for the lungs as well as the brain. Whilst our understanding of the impact of different respiratory strategies on the lungs is well understood, preclinical data involving other organs is sparse. Concerns have been raised that aggressive lung recruitment may impede cerebral haemodynamics in the preterm infant.

\section{What this study adds}

To our knowledge, this is the first study that assesses the effect of the three different aeration strategies currently being considered in clinical practice; sustained inflation, dynamic and static positive end-expiratory pressure (PEEP), on cerebral haemodynamics. We found that differing ventilation strategies did not alter carotid blood flow, carotid oxygen content or carotid oxygen delivery. Specifically, there was no difference between sustained inflation (to $35 \mathrm{cmH}_{2} \mathrm{O}$ ) and maximum PEEP levels of 8,14 and $20 \mathrm{cmH}_{2} \mathrm{O}$ applied during the first three minutes after birth.

\section{How this study might affect research, practice or policy}

Following preterm birth it is important to consider the effect of ventilation strategies on other organs, especially the brain. This preclinical study provides some reassurance that respiratory strategies designed to focus on lung aeration at birth may not impact cerebral haemodynamics in 


\section{ABSTRACT}

Objective: To examine the effect of three different ventilation strategies at birth on markers of cerebral haemodynamics and oxygenation.

Design: Animal research.

Setting: Animal research facility.

Subjects: $124-127$ day gestation apnoeic preterm lambs $(n=68)$ born via caesarean section.

Interventions: Lambs were randomised to either positive pressure ventilation with positive end-expiratory pressure (PEEP) $8 \mathrm{cmH}_{2} \mathrm{O}(\mathrm{No}-\mathrm{RM} ; \mathrm{n}=12)$, sustained inflation ( $\left.\mathrm{SI} ; \mathrm{n}=15\right)$ or a dynamic PEEP strategy (DynPEEP; $n=41$ ) at birth, followed by 90 minutes of standardised ventilation. Prior to birth a carotid artery flow probe was placed, with occlusive cannulation of the contralateral carotid artery. Carotid blood flow, ventilation data, peripheral oxygen saturation $\left(\mathrm{SpO}_{2}\right)$, heart rate and arterial blood pressure were continuously recorded, with intermittent arterial blood gas analysis at set time points.

Main outcome measures: Carotid blood flow, carotid artery oxygen content and carotid oxygen delivery (product of carotid artery blood flow and oxygen content).

Results: Overall carotid blood flow measures were comparable between strategies. The exception being mean carotid blood flow during the first 3 minutes after birth, which was significantly lower for the SI group compared to the No-RM and DynPEEP groups respectively ( $\mathrm{p}<0.0001$; repeated-measure mixed effect ANOVA). Carotid arterial oxygen content $(\mathrm{p}=0.19)$ and oxygen delivery $(\mathrm{p}=0.50)$ were similar between strategies. Maximum PEEP did not alter cerebral haemodynamic measures.

Conclusions: This is the first study to compare cerebral haemodynamics during different PEEP strategies with SI at birth. Although there were some short-term variations, there were no sustained differences. 


\section{INTRODUCTION}

Lung aeration is a fundamental component of the transition to air-breathing at birth.(1) Achieving and maintaining lung aeration is challenging for many preterm infants and there has been considerable interest in the optimal methods of supporting lung aeration in preterm infants; including the use of adequate positive end-expiratory pressure (PEEP) or an initial sustained inflation (SI).(2-6) Preclinical studies have repeatedly demonstrated that the use of adequate PEEP at birth, and preferably dynamic PEEP manoeuvres, optimises lung mechanics, aeration and reduces the risks of lung injury compared to SI.(2-6) Recent clinical trials of SI in preterm infants have suggested potentially important adverse outcomes without lung protective benefits.(7) Studies assessing ventilation strategies have primarily focused on respiratory outcomes. To date, there have been minimal reports detailing cerebrovascular responses to PEEP approaches at birth.

Cerebral blood flow (CeBF) decreases after birth in both healthy term lambs and infants as a proposed response to increasing oxygen saturation and cerebral oxygen delivery following spontaneous breathing. $(8,9)$ However, the trends of $\mathrm{CeBF}$ and oxygen delivery in preterm infants aerated by PEEP recruitment or SI remains largely unknown. Whilst its use is ubiquitous, PEEP strategies at birth have not been subjected to systematic evaluation in preterm infants resulting in the use of variable PEEP levels.(10) It has been found that SI strategy at birth increases $\mathrm{CeBF}$ and carotid oxygen content compared to a low static PEEP with tidal inflations.(11) The impact of higher PEEP levels at birth is less clear, with a recent pilot lamb study suggesting engorgement of micro-vessels and an increase in CeBF.(12) 
We aimed to determine the effect of the different PEEP level strategies or a SI to facilitate lung aeration at birth on carotid blood flow $(\mathrm{CBF})$, carotid arterial blood oxygen $(\mathrm{CAO})$ content and carotid oxygen delivery in preterm lambs.

\section{METHODS}

All techniques and procedures were approved by the Animal Ethics Committee of the Murdoch Children's Research Institute, Melbourne, Australia in accordance with National Health and Medical Research Council guidelines. This study was performed as part of a large inter-linked preterm lamb study program that aimed to determine the optimal methods of applying positive pressure ventilation (PPV) at birth. In the interest of animal reduction, and with the prior knowledge of our Animal Ethics Committee and funding body, some ventilation groups have been reported in different studies with distinctly separate aims.(2-4)

The methodology for the broader study has been reported in detail previously.(2-5) In summary, 124-127d preterm lambs born via Caesarean section under general anaesthesia to betamethasone-treated $(11.7 \mathrm{mg})$ ewes were instrumented before delivery. Instrumentation included flow probe placement around a carotid artery $(3 \mathrm{~mm}$ Transonic, AD Instruments, Sydney, Australia) and occlusive cannulation of the contralateral carotid artery and external jugular vein. At delivery, the umbilical cord was cut and the lamb weighed prior to commencing respiratory support (maximum delay 1 minute). $\mathrm{CBF}$, ventilation data, peripheral oxygen saturation $\left(\mathrm{SpO}_{2}\right)$, heart rate and arterial blood pressure were recorded throughout (200 Hz, LabChart V7, AD Instruments). Arterial blood gas (ABG) analysis was performed at fetal (Cord Intact; CI), 5, 15 minutes and then 15 minutely after birth. Ketamine and midazolam infusions were titrated to minimum doses that suppressed breathing and maintained analgesia. 
As detailed previously, $(2,4)$ lambs were randomised to either 1) PPV at a PEEP $8 \mathrm{cmH}_{2} \mathrm{O}$ with volume targeted ventilation (VTV) from birth for $90 \mathrm{~min}$ (No-RM), 2) an initial SI delivered at $35 \mathrm{cmH}_{2} \mathrm{O}$ until lung volume stability was achieved using real-time imaging (maximum 3 min), or 3) a dynamic PEEP manoeuvre delivered over 3 min using PEEP steps of $2 \mathrm{cmH}_{2} \mathrm{O}$ to a maximum of $14 \mathrm{cmH}_{2} \mathrm{O}$ (20s increments/PEEP step) or $20 \mathrm{cmH}_{2} \mathrm{O}(10 \mathrm{~s}$ increments), depending on group allocation, followed by the same stepwise decreases to a final PEEP of $8 \mathrm{cmH}_{2} \mathrm{O}$ (DynPEEP). After the initial intervention, the SI and DynPEEP groups were managed as per No-RM. Fraction of inspired oxygen and tidal volume $\left(\mathrm{V}_{\mathrm{T}}\right)$ were started at 0.3 and $7 \mathrm{ml} / \mathrm{kg}$ respectively, and both titrated using a standardised strategy to maintain pre-ductal $\mathrm{SpO}_{2} 88-94 \%$ and arterial cardon dioxide $45-60 \mathrm{mmHg}$ following the 5 minute $\mathrm{ABG}$, with surfactant therapy at 10 minutes.(2)

CBF data was extracted at 10s intervals during the fetal period, both intact cord (CI) and after cord clamping (CC), then at minutely intervals to 5 minutes after starting respiratory support, and over 20s intervals at 10, 15, 30 and 90 minutes. In the DynPEEP groups, the 1 and 2 min measures were made at maximum PEEP (80s) and end of dynamic PEEP $\left(8 \mathrm{cmH}_{2} \mathrm{O} ; 140 \mathrm{~s}\right)$. In all groups, measures from 3 to 90 minutes were at PEEP $8 \mathrm{cmH}_{2} \mathrm{O}$. From these time periods the mean waveform amplitude, maximum, minimum, and overall mean were extracted. Values were then expressed by birth weight. CAO content and carotid oxygen delivery were calculated from the $\mathrm{ABG}$ results using the following formulas:

CAO content $\left(\mathrm{mlO}_{2} / \mathrm{dLblood}\right)=\left(\mathrm{Hb}^{*} 1.36 *\left(\mathrm{SaO}_{2} / 100\right)\right)+\left(\mathrm{PaO}_{2} * 0.0031\right) .(13)$

$\mathrm{Hb}$; haemoglobin $(\mathrm{g} / \mathrm{dL}), \mathrm{SaO}_{2}$; Oxygen saturation of arterial blood (\%), $\mathrm{PaO}_{2}$; arterial partial pressure of oxygen $(\mathrm{mmHg})$ 
Carotid Oxygen Delivery (dL/min/kg)=CAO x meanCBF.(14)

CBF; carotid blood flow ( $\mathrm{ml} / \mathrm{min})$

Sample size was determined by the primary studies which were powered to lung injury primary outcomes (approximately 20 lambs/group).(2) Previous preterm lamb studies reporting $\mathrm{CBF}$ and $\mathrm{CAO}$ content have shown important differences with 6/group.(11,15). Data were analysed using a mixed-effect model (Tukey post-tests) using ventilation strategy and time as principle variables. Within the DynPEEP group, subgroup analysis comparing the maximum delivered PEEP (14 vs. $20 \mathrm{cmH}_{2} \mathrm{O}$ ) was performed using a two-way ANOVA. Analysis was performed in PRISM V9 (GraphPad, San Diego, CA) and $\mathrm{p}<0.05$ considered significant.

\section{RESULTS}

A total of 89 lambs were available for analysis. 21 lambs were excluded because of unreliable $\mathrm{CBF}$ measures related to probe-vessel contact. Table 1 and Online Supplement Table 1 describe the clinical characteristics of the 68 lambs included for analysis. Incomplete ABG data in 6 lambs resulted in 62 lambs available for calculation of CAO content and carotid oxygen delivery. The lambs were well matched. There were statistical but not clinically significant differences in the amount of fetal lung fluid drained before birth (NoRM higher), fetal $\mathrm{PaO}_{2}$ (No-RM lower) and minimum CBF and $\mathrm{PaCO}_{2}$ (both SI higher), with no significant differences in the absolute fetal CI mean and maximum CBF values.

Figure 1 shows the change in CBF over time from fetal CI (baseline). There was high intersubject variability in all groups (absolute CBF data available in the Online Supplement Figure 1). Overall, time had the greatest impact on all CBF waveform measures $(\mathrm{p}<0.0001)$, 
with mean $\mathrm{CBF}$ increasing after cord clamping before decreasing to pre-birth levels by 10 minutes. Mean $(\mathrm{p}<0.0001)$, minimum $(\mathrm{p}=0.0007)$ and maximum $(\mathrm{p}=0.0012) \mathrm{CBF}$ data were significant for combined impact of time and strategy, whilst amplitude was not $(\mathrm{p}=0.15)$. The change in mean and minimum $\mathrm{CBF}$ from fetal values was less during the first 3 minutes for the SI group. Thereafter the different ventilation strategies were comparable with no difference in later timepoints. In all groups, clamping of the umbilical cord caused the largest change in $\mathrm{CBF}$ (increase mean and minimum, decrease maximum and amplitude). Four lambs (3 DynPEEP; 7\%, $1 \mathrm{SI} ; 7 \%$ ), had a CBF that persisted at zero or negative values throughout the study (included in analysis). There was no difference in the CBF measures for the $14 \mathrm{cmH}_{2} \mathrm{O}$ and $20 \mathrm{cmH}_{2} \mathrm{O}$ DynPEEP levels (Online Supplementary Figure 2).

Figure 2 shows the absolute $\mathrm{CAO}$ content and carotid oxygen delivery over time. Irrespective of group, ventilation caused an increase in CAO content from fetal values $(\mathrm{p}<0.0001$ for time). The combined impact of time and strategy was not statistically different $(p=0.19)$. High variability in CAO content occurred in all groups at 5 minutes, with DynPEEP being lower, however this was not significant. Carotid oxygen delivery increased similarly after birth for all groups $(\mathrm{p}<0.0001$ for time and $\mathrm{p}=0.50$ combined time and strategy). No difference was found in the CAO content and carotid oxygen delivery measures for the 14 $\mathrm{cmH}_{2} \mathrm{O}$ and $20 \mathrm{cmH}_{2} \mathrm{O}$ maximum PEEP levels (Online Supplementary Figure 3).

\section{DISCUSSION}

Supporting lung aeration at birth in preterm infants improves short term respiratory outcomes. $(1,2,16)$ Despite the interest in different approaches in supporting aeration of the preterm lung at birth, systematic evaluation of cerebral haemodynamics has been limited.(11,12) To our knowledge, our study is the first to assess the effect on cerebral 
haemodynamics of the different respiratory strategies currently being considered clinically. In general, we found that the aeration strategy did not cause short-term changes to CBF, CAO content or carotid oxygen delivery. Importantly there was no significant difference in the use of transient PEEP levels between 8 and $20 \mathrm{cmH}_{2} \mathrm{O}$ in the first 3 minutes of respiratory support. Fetal stability and cord clamping practices may play a bigger role in preterm cerebral haemodynamics at birth than the respiratory strategy.

Cord clamping results in a wide range of vascular changes in preterm lambs, including an initial reduction in ventricular output and transient rebound increases in blood pressure.(17) In our study, an increase in mean $\mathrm{CBF}$ and a reduction in the amplitude of CBF occurred in groups at the time of cord clamping, prior to ventilation. This suggests that the effect of cord clamping itself is a prominent process that influences CBF. Commencing PPV prior to cord clamping in preterm lambs stabilises the cardiovascular transition at birth, including blunting of the CBF increase observed in our study. $(18,19)$ The roles of different respiratory strategies before cord clamping on cerebral haemodynamics have not been compared in the preterm infant, but our findings suggest that a difference is unlikely.

$\mathrm{CBF}$ is a commonly reported measure of cerebral haemodynamic physiology.(20,21) We found that the transient increase in mean and minimum CBF at birth was less during the SI compared to no-RM and DynPEEP (initial 3 minutes). The high intra-thoracic pressure and therefore higher pulmonary blood flow and left ventricular output created by SI ventilation may explain this difference compared to the other strategies which uses tidal (cyclic) pressure changes. There is little agreement on the effects of SI on cerebral haemodynamics. Both an increased risk of cerebrovascular injury, CBF and carotid oxygen delivery,(15) and a reduction in $\mathrm{CBF}$ compared to non-SI interventions have been reported in preterm lambs.(11) 
These conflicting results may reflect the small sample sizes in each study (approximately 6/group). This is particularly relevant given the high-level of inter-subject variability we observed in our larger SI sample of 15, highlighting the importance of appropriately powered preclinical studies. We have previously reported that SI provides no benefit in lung aeration and increases early injury markers compared to DynPEEP and No-RM.(2) The clinical implications of the different CBF patterns found in this study are unknown and cannot be used to recommend one respiratory support strategy over another.

CAO content provides a measure to assess the availability of oxygen in the blood. CAO content increased from fetal values for all ventilation strategies, indicating that each group supported cerebral oxygenation similarly and successfully. Interestingly, the DynPEEP group did not show an initial increase in CAO content from the fetal baseline until 15 minutes, compared to 5 minutes in the SI and no-RM groups. The exact cause for this is unclear. We have previously reported a lower dynamic respiratory system compliance prior to ventilation in this group of DynPEEP lambs at birth,(2) suggesting a possible fetal difference in the groups. The high variability indicates that the likely reason is a degree of transient hypoxia or asphyxia following cord clamping (weigh and moving), which is known to occur with $45 \mathrm{~s}$ delay in ventilation.(13) It is possible that the much lower sample sizes in SI and No-RM groups masked a true difference given the high degree of variability across all groups at 5 minutes. Importantly, the CAO content was similar in all groups by 10 minutes suggesting that any effect is transient. Irrespectively these findings indicate that the higher PEEP at birth may impact cerebral oxygen delivery. Future well powered studies with more arterial sampling intervals in the first 10 minutes are required. Clinical trials of DynPEEP must include cerebral complications in their analysis. 
Carotid oxygen delivery, as a function of blood flow and oxygen content, is a thorough and accurate assessment of carotid haemodynamics. We found that the carotid oxygen delivery similarly increased from fetal levels in all groups, consistent with other comparisons between SI and No-RM in preterm lambs.(11,15,22) Some preterm lamb studies have indicated a significant increase in oxygen delivery in the No-RM group compared to the SI groups, when ventilated with $100 \%$ oxygen.(11) Whilst this may indicate that the level of oxygenation influences cerebral haemodynamics, the lack of difference in our groups at 5 minutes (oxygenated in a standardised 30\% inspired oxygen) supports our assertion that achieving lung aeration rather than the means of achieving it, is the critical determinant of cerebral haemodynamics.(2)

Despite the lung protective benefits of DynPEEP at birth in preterm lambs, $(2,4)$ this strategy may result in detrimental cardiovascular impacts. Impairment of pulmonary blood flow has been reported in lambs managed with a DynPEEP approach between 4 and $10 \mathrm{cmH}_{2} \mathrm{O}$ following respiratory transition.(23) It should be noted that lung aeration was not measured in this study, limiting any interpretation of the role of volume state (overdistension or recruitment). Our study has been the first to assess the use of DynPEEP on cerebral haemodynamics during the respiratory transition. Thus, it is interesting that PEEP levels (between 8 and $20 \mathrm{cmH}_{2} \mathrm{O}$ ) did not significantly alter CBF or cerebral oxygen delivery. An important aspect of these PEEP strategies is the transient high PEEP exposure whilst the lung is clearing fetal lung fluid. Current clinical approaches to DynPEEP also constrain PEEP increases to clinical need rather than pre-fixed PEEP values which should further limit any potential risk of inadvertent high intrathoracic pressure on haemodynamics. 
A redirection of CBF from the brain was noted in four lambs, most likely during diastole. It is possible that a redirection of blood flow to the ductal and pulmonary arteries caused this.(13)

This cannot be confirmed as pulmonary or ductal blood flow was not measured in our study. As DynPEEP studies in infants are now being conducted, understanding the physiological impact of PEEP levels on pulmonary and ductal blood flow is needed.

This study has limitations. Data was sourced from a large biobank of inter-linked preterm lamb studies primarily assessing lung injury. Cerebral haemodynamics were not the primary outcome of these studies leading to some lambs being excluded due to unreliable CBF data. We studied anaesthetised apnoeic lambs, a common preclinical model, but not representative of clinical practice. CBF and cerebral oxygenation measures are difficult in humans and ultrasound measures or Near-InfraRed Spectroscopy may be more translatable tools. $(24,25)$ Assessment of cerebral flow dynamics was made via the common practice of measuring from a single carotid artery, $(19,26)$ with occlusion of the other. Extrapolating these measures to global cerebral haemodynamics requires caution, as unilateral occlusion may result in changes to the flow dynamics of the contralateral side.(21) Further, our measures should not be assumed to represent the cerebral microvascular bed, with a recent preterm lamb pilot study suggesting large and small cerebral vessel behaviour is not always uniform.(12) Finally, we did not measure cerebral injury as an outcome.

\section{Conclusion}

There is a paucity of information on the cerebral haemodynamic effects of respiratory strategy at birth in preterm infants, despite the clear risk of injury in this population. Reassuringly respiratory strategy did not impact cerebral haemodynamics, suggesting that 
clinicians can focus on strategies that optimise cardiorespiratory outcomes during the transition to air breathing.

Acknowledgments: The authors acknowledge Regina Oakley for assistance in lamb management and preparation of some of the gas exchange and lung mechanics data, and Sarah White and Rebecca Sutton for assistance in preparation of the ewes. 


\section{FIGURE LEGENDS}

Figure 1. Change in carotid blood flow (CBF) waveform for different ventilation strategies from fetal (cord intact) measures across time.

Figure 1. Change in mean $(\mathbf{A} ; p<0.0001)$, minimum $(\mathbf{B} ; p=0.0007)$, maximum $(\mathbf{C} ; p=0.0012)$ and amplitude $(\mathbf{D} ; \mathrm{p}=0.1500)$ of the carotid blood flow $(\mathrm{CBF})$ waveform from fetal measures with the cord intact $(\mathrm{CI})$, following cord clamping (CC) before ventilation and then 90 minutes of positive pressure ventilation in the No-RM (black circles), DynPEEP (open circles) and SI (grey diamond) recruitment groups. DynPEEP data represents pooled data for both the 14 and $20 \mathrm{cmH}_{2} \mathrm{O}$ maximum PEEP. Fetal period without any ventilation shown in grey background. Birth; first 10 s after commencing allocated recruitment strategy. All p values represent the overall $\mathrm{p}$ value using a mixed effects model (time and strategy combined). $\dagger$ SI vs No-RM, * SI vs DynPEEP $\mathrm{p}<0.05$ Tukey post-tests. All data mean and standard deviation.

Figure 2. Absolute carotid artery oxygen (CAO) content and carotid oxygen delivery for different ventilation strategies across time.

Figure 2. Absolute carotid arterial oxygen $(\mathrm{CAO})$ content $(\mathbf{A} ; \mathbf{p}=0.19)$ and carotid oxygen delivery $(\mathbf{B} ; \mathrm{p}=0.50)$ in the fetal period (apnoeic cord intact $(\mathrm{CI})$ and then at select timepoints during 90 minutes of positive pressure ventilation following the allocated 3 minute aeration strategy at birth for the No-RM (black circles), DynPEEP (open circles) and SI groups (grey diamonds). Birth; first 10s after commencing allocated recruitment strategy. All p values mixed effects model (time and strategy combined). All data mean and standard deviation. 
Table 1. Lamb Characteristics

\begin{tabular}{|c|c|c|c|c|c|c|c|c|c|c|c|c|c|c|c|}
\hline \multirow[t]{2}{*}{ Group } & \multirow[t]{2}{*}{$\mathbf{n}$} & \multirow[t]{2}{*}{ GA (d) } & \multirow{2}{*}{$\begin{array}{l}\text { Weight } \\
\text { (kg) }\end{array}$} & \multirow{2}{*}{$\begin{array}{l}\text { Gender } \\
(\mathbf{F}: \mathbf{M})\end{array}$} & \multirow{2}{*}{$\begin{array}{l}\text { Parity } \\
\text { (S:T) }\end{array}$} & \multirow{2}{*}{$\begin{array}{l}\text { Fetal } \\
\text { Fluid } \\
\text { (ml/kg) }\end{array}$} & \multirow{2}{*}{$\begin{array}{l}\text { Static } \mathrm{C}_{\mathrm{RS}} \\
\left(\mathrm{ml} / \mathrm{kg} / \mathrm{cmH}_{2} \mathrm{O}\right)\end{array}$} & \multicolumn{4}{|c|}{ Fetal Arterial Blood Gas } & \multicolumn{4}{|c|}{ Cerebral Blood Flow (ml/kg/min) } \\
\hline & & & & & & & & pH & $\begin{array}{l}\mathrm{PaCO}_{2} \\
(\mathrm{mmHg})\end{array}$ & $\begin{array}{l}\mathrm{PaO}_{2} \\
(\mathrm{mmHg})\end{array}$ & $\begin{array}{l}\mathrm{BiC} \\
(\mathrm{mmol})\end{array}$ & Height & Min & Max & Mean \\
\hline No-RM & 12 & $\begin{array}{l}126 \\
(1.0) \\
\end{array}$ & $\begin{array}{l}3.37 \\
(0.57) \\
\end{array}$ & $6: 6$ & $1: 11$ & $\begin{array}{l}19.0 \\
(6.9) \\
\end{array}$ & $1.35(0.20)$ & $\begin{array}{l}7.34 \\
(0.05) \\
\end{array}$ & $\begin{array}{l}46.0 \\
(5.7) \\
\end{array}$ & $\begin{array}{l}23.3 \\
(3.5) \\
\end{array}$ & $\begin{array}{l}24.0 \\
(2.2) \\
\end{array}$ & $\begin{array}{l}50.3 \\
(14.5) \\
\end{array}$ & $\begin{array}{l}0.9 \\
(3.1) \\
\end{array}$ & $\begin{array}{l}15.6 \\
(4.4) \\
\end{array}$ & $\begin{array}{l}51.3 \\
(14.2) \\
\end{array}$ \\
\hline SI & 15 & $\begin{array}{l}125.4 \\
(1.0)\end{array}$ & $\begin{array}{l}3.24 \\
(0.43)\end{array}$ & $5: 10$ & $2: 13$ & $\begin{array}{l}17.6 \\
(5.8)\end{array}$ & $1.29(0.26)$ & $\begin{array}{l}7.35 \\
(0.07)\end{array}$ & $\begin{array}{l}52.0 \\
(7.6)\end{array}$ & $\begin{array}{l}25.9 \\
(6.1)\end{array}$ & $\begin{array}{l}24.8 \\
(2.8)\end{array}$ & $\begin{array}{l}53.7 \\
(31.1)\end{array}$ & $\begin{array}{l}3.3 \\
(5.9)\end{array}$ & $\begin{array}{l}19.5 \\
(10.8)\end{array}$ & $\begin{array}{l}57.1 \\
(30.5)\end{array}$ \\
\hline DynPEEP & 41 & $\begin{array}{l}125.3 \\
(1.0) \\
\end{array}$ & $\begin{array}{l}3.39 \\
(0.33) \\
\end{array}$ & $26: 15$ & $3: 38$ & $\begin{array}{l}17.4 \\
(5.1)\end{array}$ & $1.21(0.20)$ & $\begin{array}{l}7.34 \\
(0.06) \\
\end{array}$ & $\begin{array}{l}47.3 \\
(7.0)\end{array}$ & $\begin{array}{l}27.5 \\
(5.4) \\
\end{array}$ & $\begin{array}{l}23.5 \\
(2,7)\end{array}$ & $\begin{array}{l}51.0 \\
(16.7) \\
\end{array}$ & $\begin{array}{l}-0.3 \\
(4.2) \\
\end{array}$ & $\begin{array}{l}14.4 \\
(5.9) \\
\end{array}$ & $\begin{array}{l}50.4 \\
(15.8) \\
\end{array}$ \\
\hline p value & & 0.13 & 0.43 & 0.13 & 0.78 & $<0.0001$ & 0.11 & 0.95 & 0.049 & 0.009 & 0.28 & 0.87 & 0.04 & 0.64 & 0.06 \\
\hline
\end{tabular}

Abbreviations: GA; gestational age, $\mathrm{F}$; female, $\mathrm{M}$; male, $\mathrm{S}$; singleton, $\mathrm{T}$; multiparity, $\mathrm{C}_{\mathrm{RS}}$; compliance, $\mathrm{PaCO}_{2}$; partial arterial pressure of carbon dioxide, $\mathrm{PaO}_{2}$; partial arterial pressure of oxygen, Bic; bicarbonate.

Cerebral blood flow values whilst umbilical cord intact. All data mean (SD) or ratio. All p values one-way ANOVA or chi-test as appropriate. 


\section{REFERENCES}

1. Hooper SB, Te Pas AB, Kitchen MJ. Respiratory transition in the newborn: a three-phase process. Arch Dis Child Fetal Neonatal Ed. 2016;101(3):F266-71.

2. Tingay DG, Pereira-Fantini PM, Oakley R, McCall KE, Perkins EJ, Miedema M, et al. Gradual Aeration at Birth Is More Lung Protective Than a Sustained Inflation in Preterm Lambs. Am J Respir Crit Care Med. 2019;200(5):608-16.

3. Tingay DG, Togo A, Pereira-Fantini PM, Miedema M, McCall KE, Perkins EJ, et al. Aeration strategy at birth influences the physiological response to surfactant in preterm lambs. Arch Dis Child Fetal Neonatal Ed. 2019;104(6):F587-F93.

4. Tingay DG, Rajapaksa A, Zannin E, Pereira-Fantini PM, Dellaca RL, Perkins EJ, et al. Effectiveness of individualized lung recruitment strategies at birth: an experimental study in preterm lambs. Am J Physiol Lung Cell Mol Physiol. 2017;312(1):L32-L41.

5. Tingay DG, Rajapaksa A, Zonneveld CE, Black D, Perkins EJ, Adler A, et al. Spatiotemporal Aeration and Lung Injury Patterns Are Influenced by the First Inflation Strategy at Birth. Am J Respir Cell Mol Biol. 2016;54(2):263-72.

6. Tingay DG, Lavizzari A, Zonneveld CE, Rajapaksa A, Zannin E, Perkins E, et al. An individualized approach to sustained inflation duration at birth improves outcomes in newborn preterm lambs. Am J Physiol Lung Cell Mol Physiol. 2015;309(10):L1138-49.

7. Kirpalani H, Ratcliffe SJ, Keszler M, Davis PG, Foglia EE, Te Pas A, et al. Effect of Sustained Inflations vs Intermittent Positive Pressure Ventilation on Bronchopulmonary Dysplasia or Death Among Extremely Preterm Infants: The SAIL Randomized Clinical Trial. JAMA. 2019;321(12):1165-75.

8. Bendeck MP, Langille BL. Changes in blood flow distribution during the perinatal period in fetal sheep and lambs. Can J Physiol Pharmacol. 1992;70(12):1576-82. 
9. Connors G, Hunse C, Gagnon R, Richardson B, Han V, Rosenberg H. Perinatal assessment of cerebral flow velocity wave forms in the human fetus and neonate. Pediatr Res. 1992;31(6):649-52.

10. Sweet DG, Carnielli V, Greisen G, Hallman M, Ozek E, Te Pas A, et al. European Consensus Guidelines on the Management of Respiratory Distress Syndrome - 2019 Update. Neonatology. 2019;115(4):432-50.

11. Sobotka KS, Hooper SB, Allison BJ, Te Pas AB, Davis PG, Morley CJ, et al. An initial sustained inflation improves the respiratory and cardiovascular transition at birth in preterm lambs. Pediatr Res. 2011;70(1):56-60.

12. Inocencio IM, Tran NT, Nakamura S, Khor SJ, Wiersma M, Stoecker K, et al. Increased peak end-expiratory pressure in ventilated preterm lambs changes cerebral microvascular perfusion: direct synchrotron microangiography assessment. Journal of applied physiology. 2020;129(5):1075-84.

13. Smolich JJ, Kenna KR, Cheung MM. Onset of asphyxial state in nonrespiring interval between cord clamping and ventilation increases hemodynamic lability of birth transition in preterm lambs. J Appl Physiol (1985). 2015;118(6):675-83.

14. Lister G, Walter TK, Versmold HT, Dallman PR, Rudolph AM. Oxygen delivery in lambs: cardiovascular and hematologic development. Am J Physiol. 1979;237(6):H66875.

15. Sobotka KS, Hooper SB, Crossley KJ, Ong T, Schmolzer GM, Barton SK, et al. Single Sustained Inflation followed by Ventilation Leads to Rapid Cardiorespiratory Recovery but Causes Cerebral Vascular Leakage in Asphyxiated Near-Term Lambs. PLoS One. 2016;11(1):e0146574.

16. Jobe AH, Hillman N, Polglase G, Kramer BW, Kallapur S, Pillow J. Injury and inflammation from resuscitation of the preterm infant. Neonatology. 2008;94(3):190-6. 
17. Smolich JJ, Kenna KR, Phillips SE, Mynard JP, Cheung MMM, Lambert GW. Characteristics and physiological basis of falls in ventricular outputs after immediate cord clamping at delivery in preterm fetal lambs. J Physiol. 2021;599(15):3755-70.

18. Bhatt S, Alison BJ, Wallace EM, Crossley KJ, Gill AW, Kluckow M, et al. Delaying cord clamping until ventilation onset improves cardiovascular function at birth in preterm lambs. J Physiol. 2013;591(8):2113-26.

19. Polglase GR, Dawson JA, Kluckow M, Gill AW, Davis PG, Te Pas AB, et al. Ventilation onset prior to umbilical cord clamping (physiological-based cord clamping) improves systemic and cerebral oxygenation in preterm lambs. PLoS One. 2015;10(2):e0117504.

20. Covert RF, Schreiber MD, Torgerson LJ, Torgerson RW, Miletich DJ. Prediction of cerebral blood flow in fetal lambs by carotid artery ultrasonic flow transducer. Reprod Fertil Dev. 1996;8(1):157-62.

21. van Bel F, Roman C, Klautz RJ, Teitel DF, Rudolph AM. Relationship between brain blood flow and carotid arterial flow in the sheep fetus. Pediatr Res. 1994;35(3):329-33.

22. Barton SK, Moss TJ, Hooper SB, Crossley KJ, Gill AW, Kluckow M, et al. Protective ventilation of preterm lambs exposed to acute chorioamnionitis does not reduce ventilation-induced lung or brain injury. PLoS One. 2014;9(11):e112402.

23. Polglase GR, Hooper SB, Gill AW, Allison BJ, McLean CJ, Nitsos I, et al. Cardiovascular and pulmonary consequences of airway recruitment in preterm lambs. Journal of applied physiology. 2009;106(4):1347-55.

24. Vesoulis ZA, Mintzer JP, Chock VY. Neonatal NIRS monitoring: recommendations for data capture and review of analytics. J Perinatol. 2021;41(4):675-88. 
25. Ericksen K, Alpan G, La Gamma EF. Effect of ventilator modes on neonatal cerebral and peripheral oxygenation using near-infrared spectroscopy. Acta Paediatr. 2021;110(4):1151-6.

26. El-Sabbagh AM, Gray BW, Shaffer AW, Bryner BS, Church JT, McLeod JS, et al. Cerebral Oxygenation of Premature Lambs Supported by an Artificial Placenta. ASAIO J. 2018;64(4):552-6. 

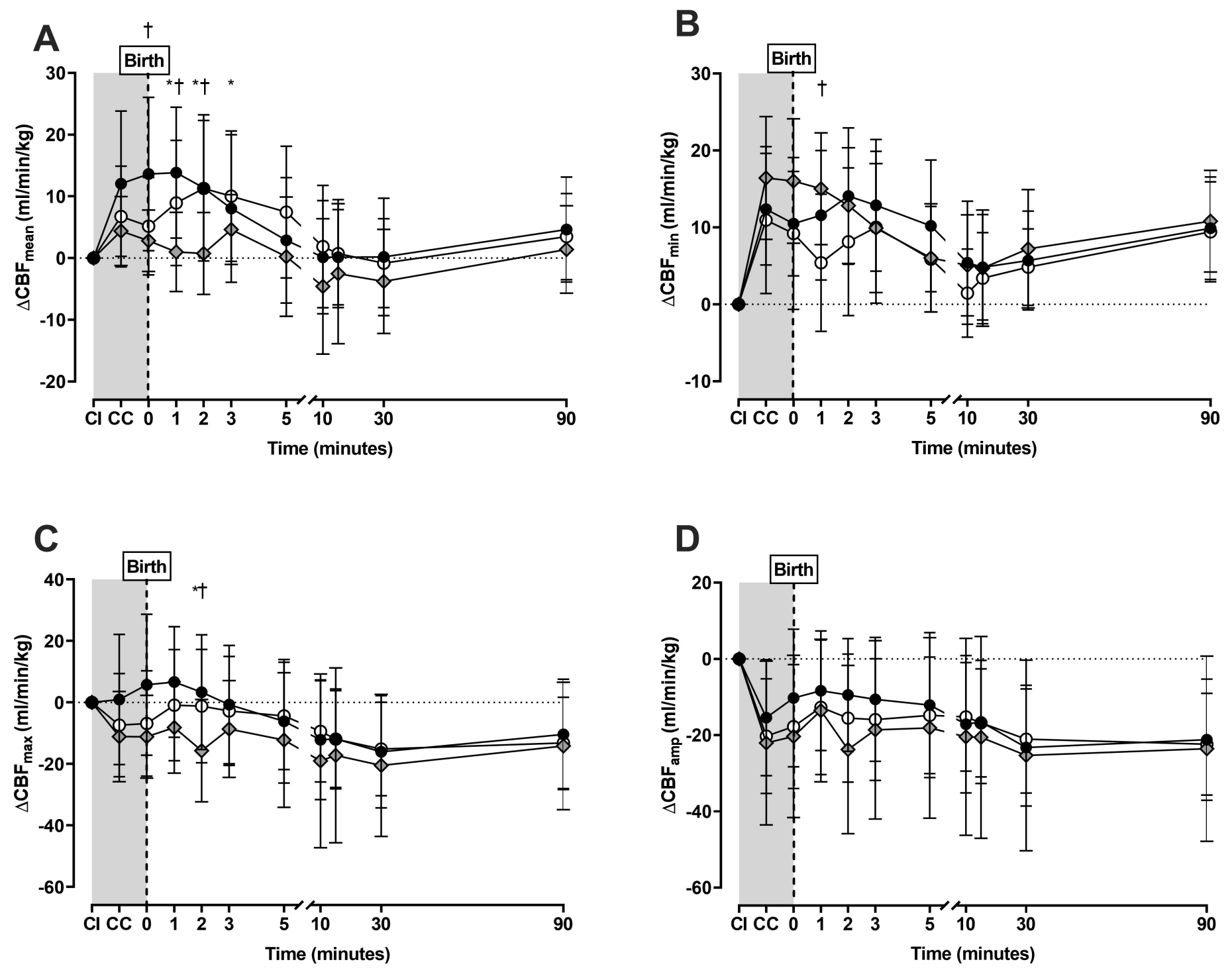

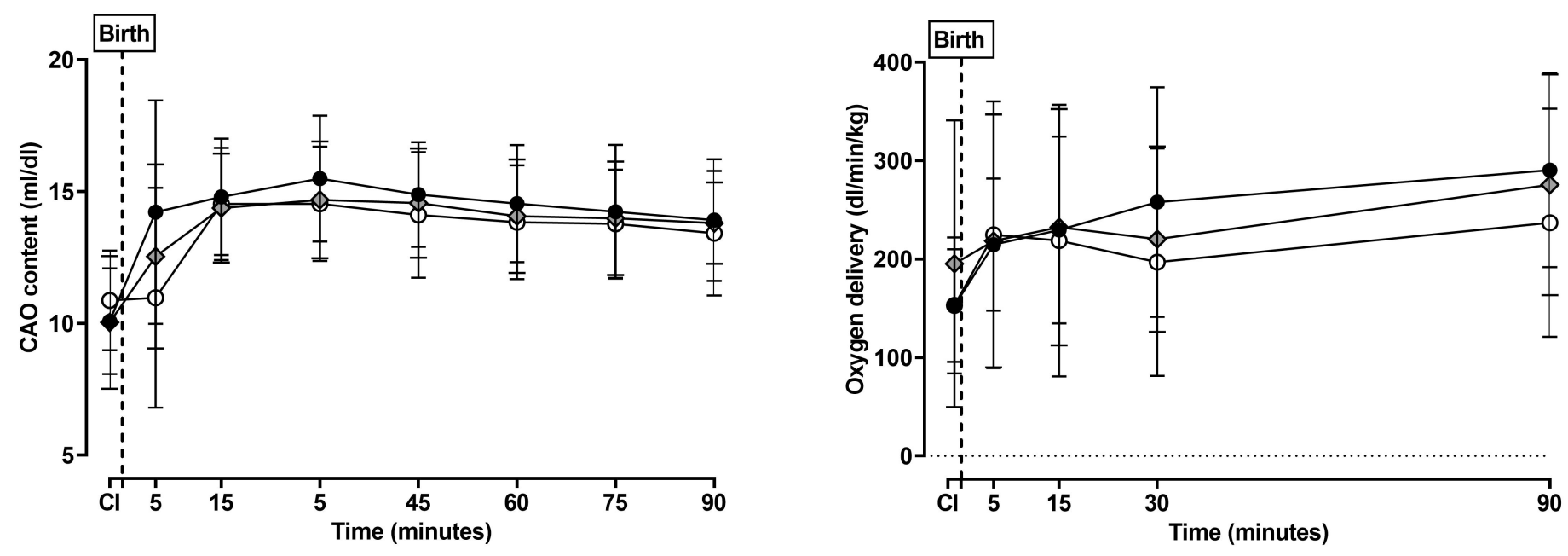